

\section{Capacity Requirements to Support Inter-Balancing Area Wind Delivery}

Brendan Kirby and Michael Milligan

Prepared under Task No. WER95501

Technical Report NREL/TP-550-46274 July 2009

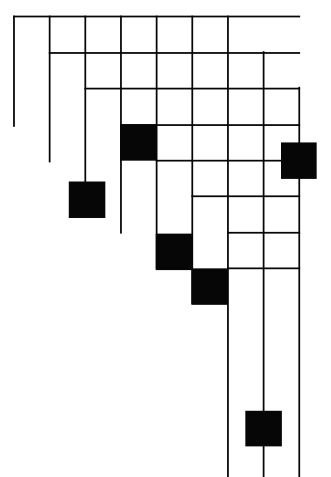




\section{NOTICE}

This report was prepared as an account of work sponsored by an agency of the United States government. Neither the United States government nor any agency thereof, nor any of their employees, makes any warranty, express or implied, or assumes any legal liability or responsibility for the accuracy, completeness, or usefulness of any information, apparatus, product, or process disclosed, or represents that its use would not infringe privately owned rights. Reference herein to any specific commercial product, process, or service by trade name, trademark, manufacturer, or otherwise does not necessarily constitute or imply its endorsement, recommendation, or favoring by the United States government or any agency thereof. The views and opinions of authors expressed herein do not necessarily state or reflect those of the United States government or any agency thereof.

Available electronically at http://www.osti.gov/bridge

Available for a processing fee to U.S. Department of Energy and its contractors, in paper, from:

U.S. Department of Energy

Office of Scientific and Technical Information

P.O. Box 62

Oak Ridge, TN 37831-0062

phone: 865.576 .8401

fax: 865.576 .5728

email: mailto:reports@adonis.osti.gov

Available for sale to the public, in paper, from:

U.S. Department of Commerce

National Technical Information Service

5285 Port Royal Road

Springfield, VA 22161

phone: 800.553.6847

fax: 703.605.6900

email: orders@ntis.fedworld.gov

online ordering: http://www.ntis.gov/ordering.htm 


\title{
Capacity Requirements to Support Inter-Balancing Area Wind Delivery
}

\author{
Brendan Kirby \\ National Renewable Energy Laboratory \\ Consultant \\ 2307 Laurel Lake Rd \\ Knoxville, TN 37932 \\ kirbybj@ieee.org \\ Michael Milligan \\ National Renewable Energy Laboratory \\ 1617 Cole Blvd., Golden, CO 80401 \\ michael milligan@nrel.gov
}

Topics: $\quad$ Capacity Requirements

Power System Operations and Wind Energy

\begin{abstract}
Wind power plants are sometimes hosted by balancing areas that export the wind energy to neighboring areas. In cases like this, energy scheduling constraints can impose capacity obligations on the host balancing area that are not necessary for reliability, and have no benefit to either the host or the receiving balancing area. This paper examines the capacity requirements that arise as wind generation is integrated into the power system and how those requirements change depending on where the wind energy is ultimately delivered. Wind energy that is used to serve load within the balancing area imposes one set of requirements while wind energy that is delivered to another balancing area imposes a different set of requirements. In some cases significant excess conventional generation capacity is required within the host balancing area simply to satisfy inter-balancing-area scheduling rules. The paper examines how these capacity requirements arise and what purpose they physically serve. We then propose methods that can reduce or eliminate this excess capacity requirement while enabling inter-area transfers of wind energy, decreasing integration cost and increasing system reliability.
\end{abstract}

\section{Introduction}

There has been considerable work in recent years on wind integration impacts and costs. Most of these studies have featured some combination of statistical analysis on load and wind data, along with detailed system simulations of at least one year, using hourly data. A common finding among the studies is a need for increased operating reserve to help cover the additional variability that wind brings to the system. In most cases, however, this operating reserve is not rigorously defined, which has lead, we believe, to some fundamental misunderstanding of how wind, load, and reserves interact. The erroneous belief is that wind consumes system capacity. In fact, during discussions that 
we were involved with as part of the Northwest Wind Integration Action Plan (NWIAP), the opinion was expressed that wind likely has a negative capacity value.

These misunderstandings arise from inconsistent use of the term 'capacity' and about the relationship to ramping requirements in systems with significant wind penetrations. In an attempt to help clarify this issue, we develop several simple 'thought experiments' that are designed to focus on the characteristics of wind and its impact on system balance. We then examine the simple results in the light of public data from wind integration on the BPA system.

\section{Wind Serving Loads within the Host Balancing Area}

The starting point for our analysis is the assumption that wind energy is introduced into a power system that can already meet its load obligations, and the wind will be used within the balancing area (BA). (We will relax this assumption in a later section of this paper.) This assumption has several implications. First, there is sufficient capacity (installed generation) to meet the system peak load plus a reserve margin. Wind's primary value is in saving fuel (or water). If the non-wind generation could meet the load without depending on wind energy, then the load can be met after wind is added to the system. Second, load ramps can be met and balanced by the existing generator fleet; there is sufficient ramping capability over all relevant time scales from seconds, minutes to hours or longer for the existing non-wind system. Note that we have not assumed anything about the ramp requirements of the system once wind has been added to the system; that will be discussed shortly. Third, there is sufficient energy to satisfy customer demand without depending on the wind energy.

Figure 1 illustrates a simple case of a flat load and the required generation. In this simple case we do not consider reserve requirements: the installed capacity curve is offset from the load curve just enough so that both can be seen. Said simply, the power system needs just enough generation to meet load.

\section{Regulation}

Because there is load variability minute to minute, however, Figure 2 shows that there must be sufficient generation to cover the maximum load, taking into account the short-term variability. Because the maximum load will exceed the average load for the period, the average load plus the maximum of the regulation impact must be covered by the available generating capacity. This regulating reserve does require more capacity than the flat load and there is an "extra capacity" shown in Figure 2. Wind will generally increase this regulation requirement modestly and will therefore have an impact on minute-to-minute regulating capacity requirements. Minute-to-minute variability tends not to be correlated between individual loads, between individual wind generators, and between wind generators and loads. Consequently, total variability does not increase as fast as the energy requirements for loads or the energy contributions from wind generators as power system size increases. Further, it is almost always advantageous to aggregate as much load and as much wind together and to provide regulation compensation for the aggregation. Larger balancing areas, or multiple balancing areas that combine their variability through ACE diversity sharing or other means, have relatively lower regulation requirements than smaller balancing areas that deal with their variability individually. 


\section{Capacity to Serve Flat Load}

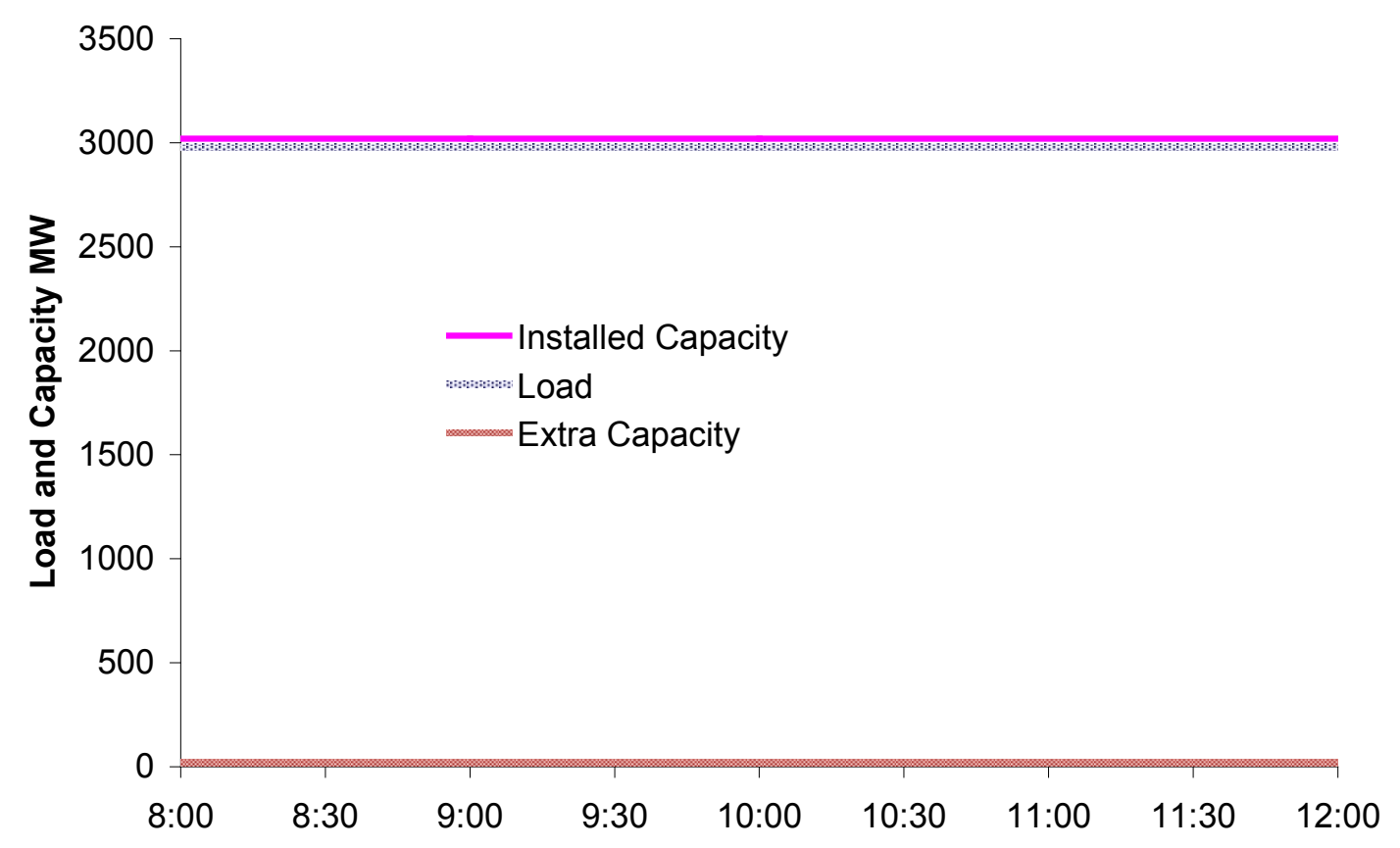

Figure 1. Flat load requires enough installed capacity to cover load.

\section{Capacity to Serve Varying Load}

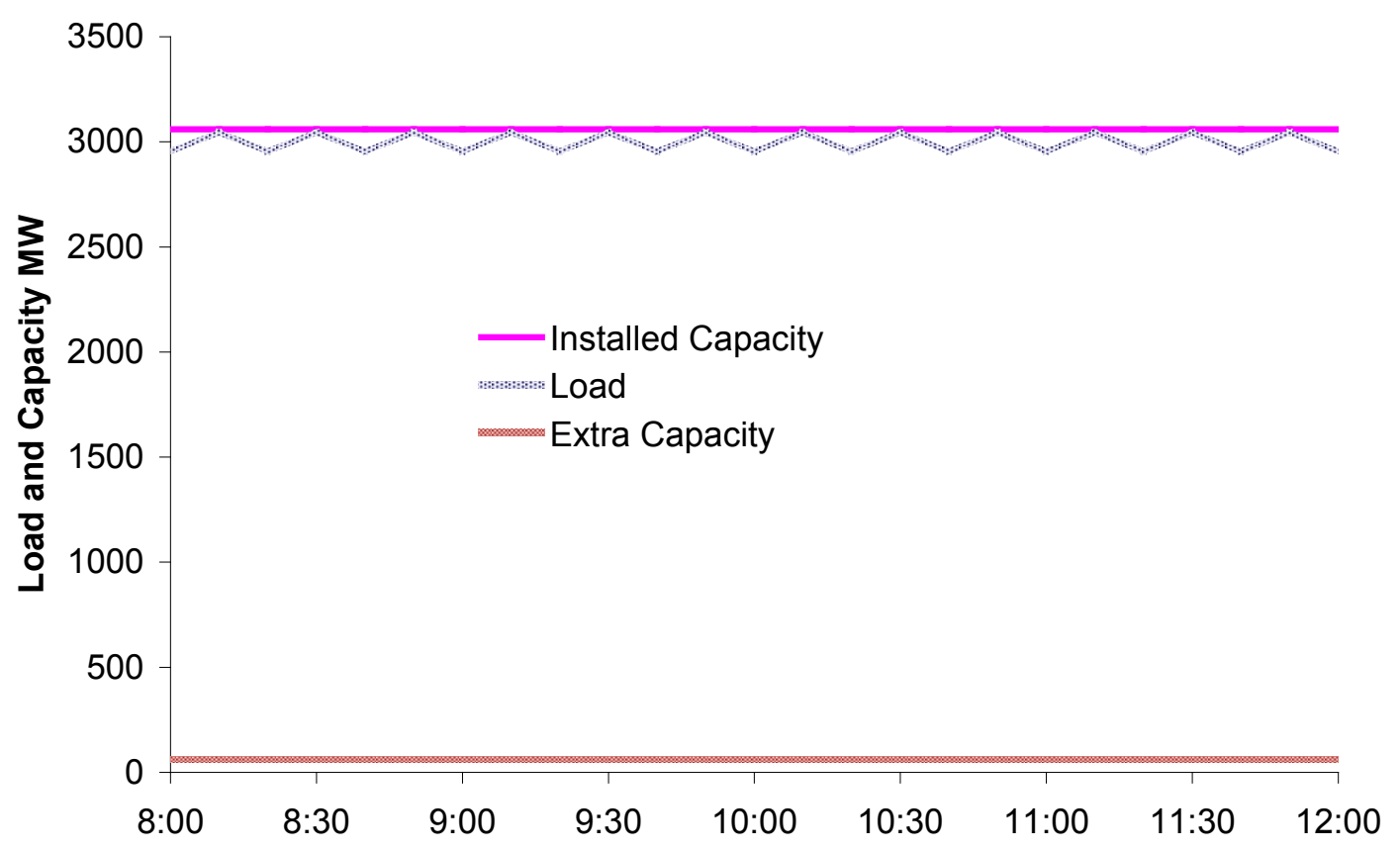

Figure 2. Minute-to-minute regulation requires additional capacity. 


\section{Ramping}

Intera- and inter-hour ramping requirements are much greater than minute-to-minute regulation requirements, but the characteristics are different. Figure 3 shows the impact of the morning load ramp. Because we wish to investigate wind's impact on ramping requirements, as distinct from the minute-to-minute regulation variability, and to keep the examples simple and clear, we will remove the minute-to-minute variability for the rest of the discussion (we will discuss the interesting potential for wind plants to supply regulation later in the paper). What is apparent from the graph is that there is no need for additional capacity to provide for the load ramp. Capacity that will be used to supply energy from 10:00 to 12:00 is available to follow the 9:00 to 10:00 ramp because it was not supplying energy before 9:00. Additional movement is required from the existing capacity so that the system remains in balance, but no additional capacity is required beyond what is needed to meet the peak hour energy requirement.

\section{Capacity to Serve Ramping Load}

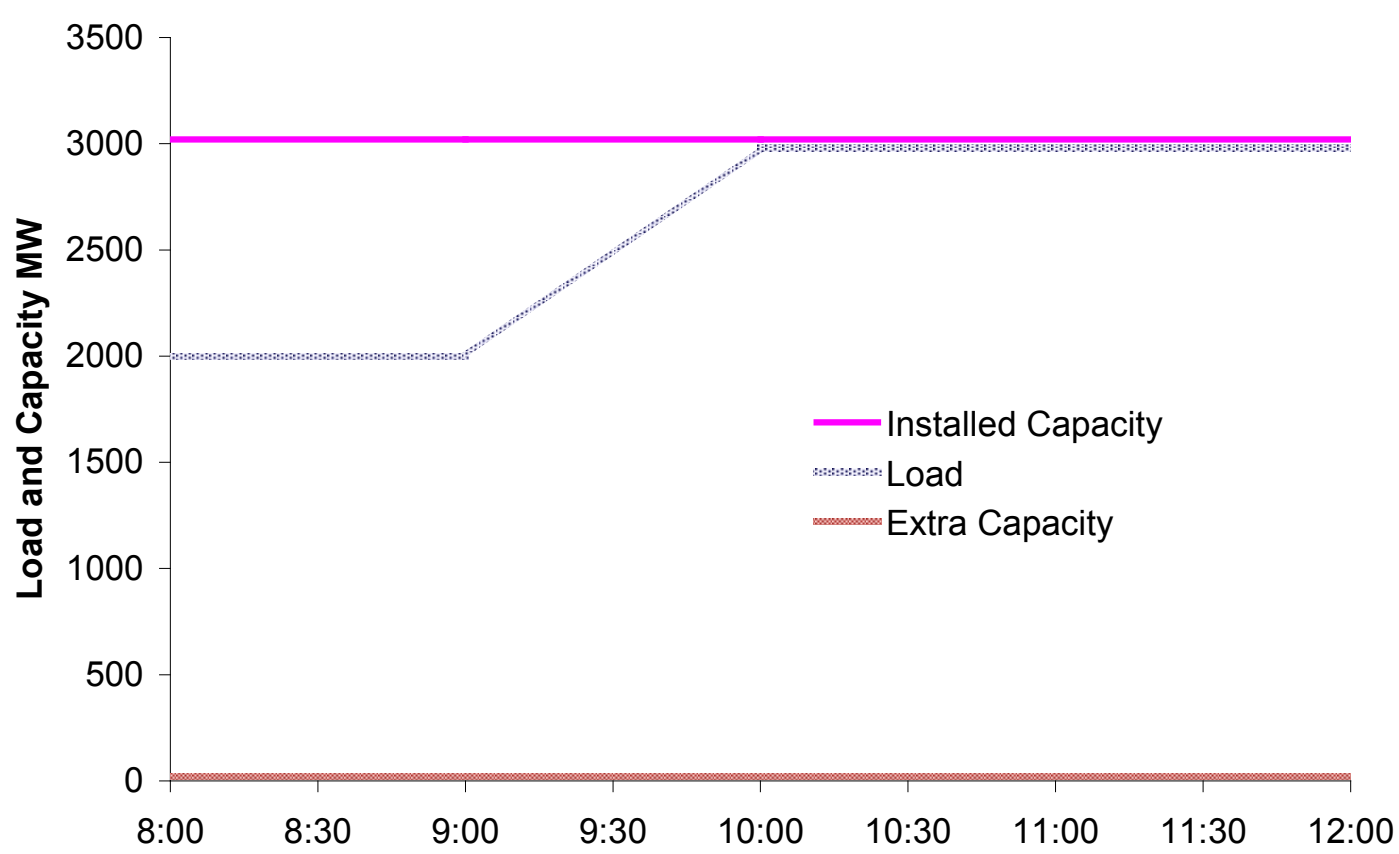

Figure 3. Load ramps do not require additional capacity, just additional movement of existing capacity.

We now create a simple scenario with constant load and variable wind. For this example, we assume that wind energy is only produced from 8:00-10:00, and hold the load constant. Figure 4 shows 500 MW wind output from 8:00-9:00, ramping down from 9:00-10:00. The wind energy delays the need for $500 \mathrm{MW}$ of other generation until 9:00, at which time the wind begins to reduce its output, causing a need for an offsetting increase in the other generation. From 10:00-12:00 the conventional generation is positioned exactly where it was in the no-wind case. From 8:00-9:00 there is a reduction in the conventional capacity required compared to the no-wind case, and this reduction is gradually reduced from 9:00-10:00, but there is never an increase in conventional generation capacity above what was already required to serve load. 


\section{Wind Serves Internal BA Load}

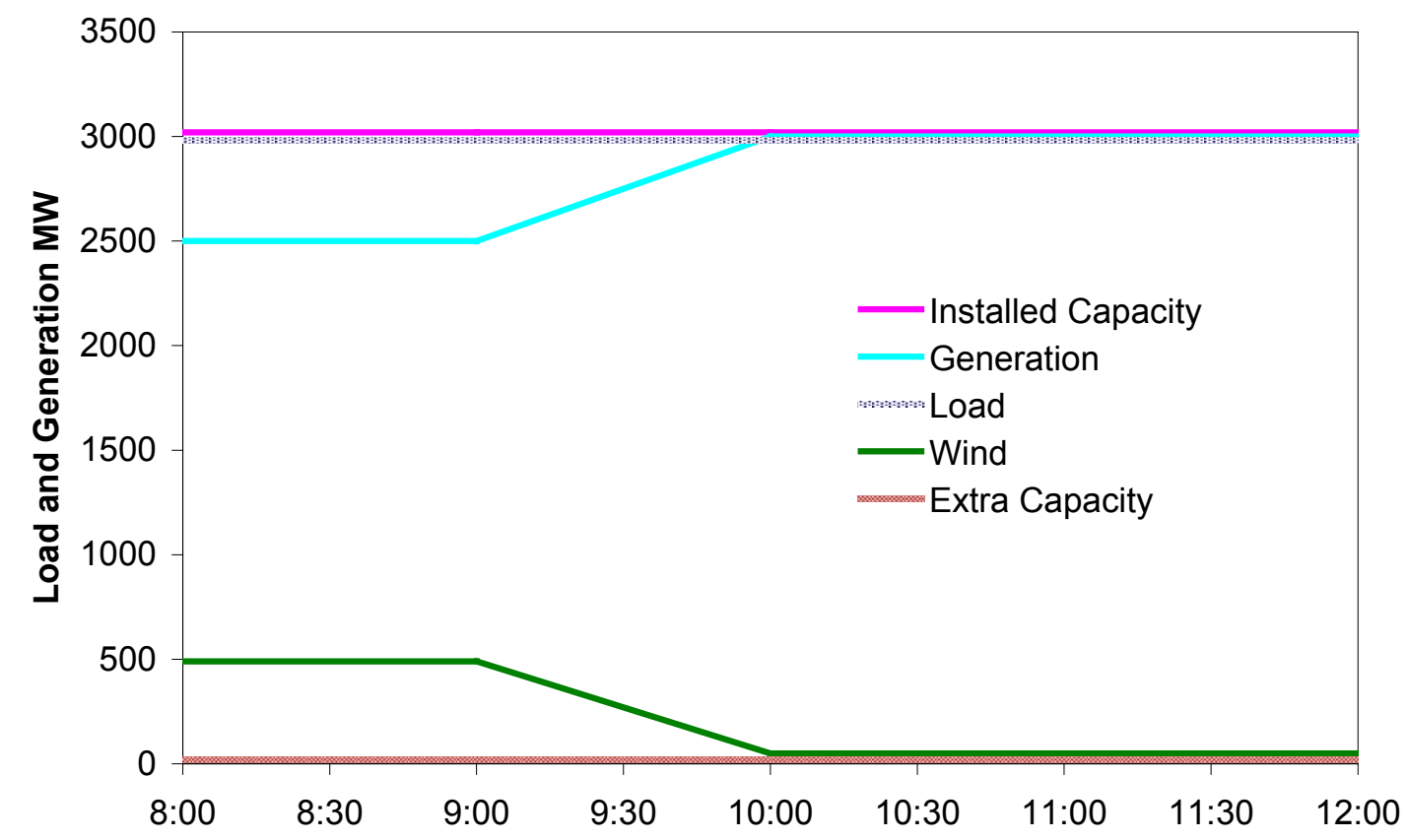

Figure 4. Wind serving loads within the host BA does not require additional capacity, just additional movement of existing capacity.

Our simplistic graph does not show the variability of the wind during the 8:00-10:00 period. Suppose now that the wind varies between 300-500 MW during the period 8:00-9:00. In this case, instead of a reduction in conventional generation of $500 \mathrm{MW}$ for the hour, this reduction would vary between 300-500 MW. However, it is clear that there is no need for conventional capacity beyond what is already required for the load.

It is also clear that the addition of wind does not increase capacity requirements when wind is used to serve internal BA loads. Later we will discuss the additional off-system energy sales opportunities created when wind serves internal BA loads, and limitations on those opportunities imposed by imperfect forecasts, but first we will discuss the conceptually simpler case where wind simply serves off-system loads. 


\section{Wind Serving Loads External to the Host Balancing Area (BA)}

In the previous section we showed that when wind is serving load within the host BA, it does not require additional capacity. In this section we show that when wind serves load outside of the host BA, there is an additional capacity requirement. That additional capacity requirement is tied to the nature of transactions between BAs, and is not due to a physical capacity need, however. We also show that there are institutional mechanisms that can be used to reduce or eliminate this capacity need. For this example, we initially assume that the region runs hourly dispatch/market schedules for inter-BA transactions. We show how this assumption affects the outcome in a later section of this paper.

Figure 5 illustrates our example. Wind generation in one BA is being delivered to another BA. Just before 9:30, the wind generation drops over a 15-minute period. The region only allows inter-BA schedules to change at the top of each hour, however, so the physical host BA must continue delivery of the scheduled wind energy from its non-wind fleet until the top of the next hour. In this case, the host BA generation must exceed its load for the duration of the market period; this represents a capacity requirement on the host. ${ }^{1}$

\section{Wind Serves External Load}

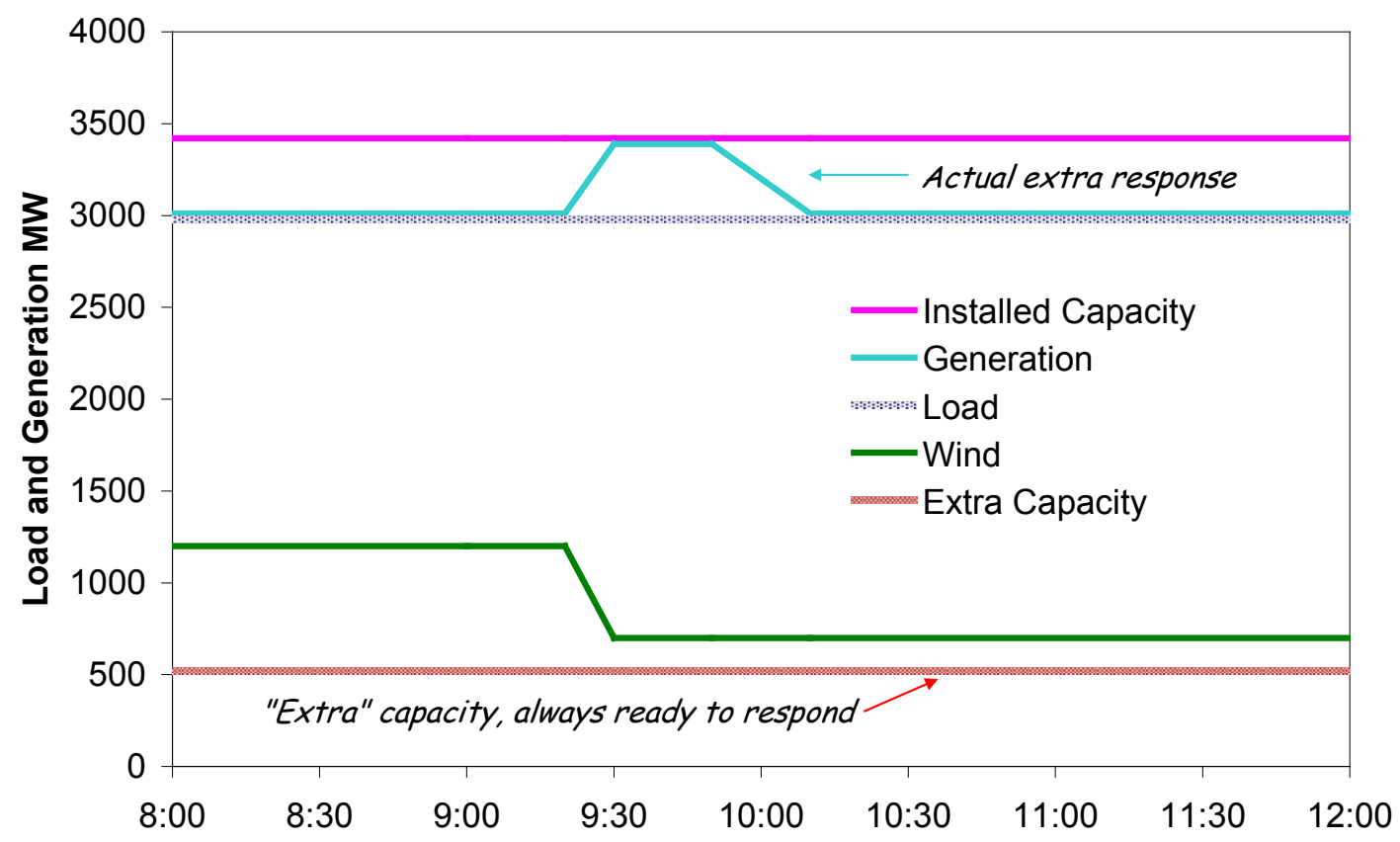

Figure 5. Wind serving loads outside the host BA does require additional capacity; the host covers the wind delivery until the end of the scheduling period, 1 hour.

\footnotetext{
${ }^{1}$ The actual amount of "extra" capacity required depends on the maximum credible wind reduction during the hour. In this simple example the wind drops $500 \mathrm{MW}$ from $1200 \mathrm{MW}$ to $700 \mathrm{MW}$ and that is the largest drop ever expected. Actual wind performance is more complex but wind output does not normally drop from full to zero within an hour for a large wind fleet.
} 
Unfortunately, from the point of view of the receiving BA, the capacity used by the host to maintain the wind schedule is of no benefit. The receiver cannot use this capacity, and the only real impact is a delay in response speed for the generators in the receiving BA. This is shown in Figure 6. Because the market period clears hourly, the delivered wind power differs from the actual wind power as a result of the host covering the hourly schedule. The receiver does need to respond to the change in wind power, but this response does not happen until the next market period. Therefore, there is a delay in the required response from the receiver, but there is no capacity advantage for the receiver.

\section{External BA Receives Wind}

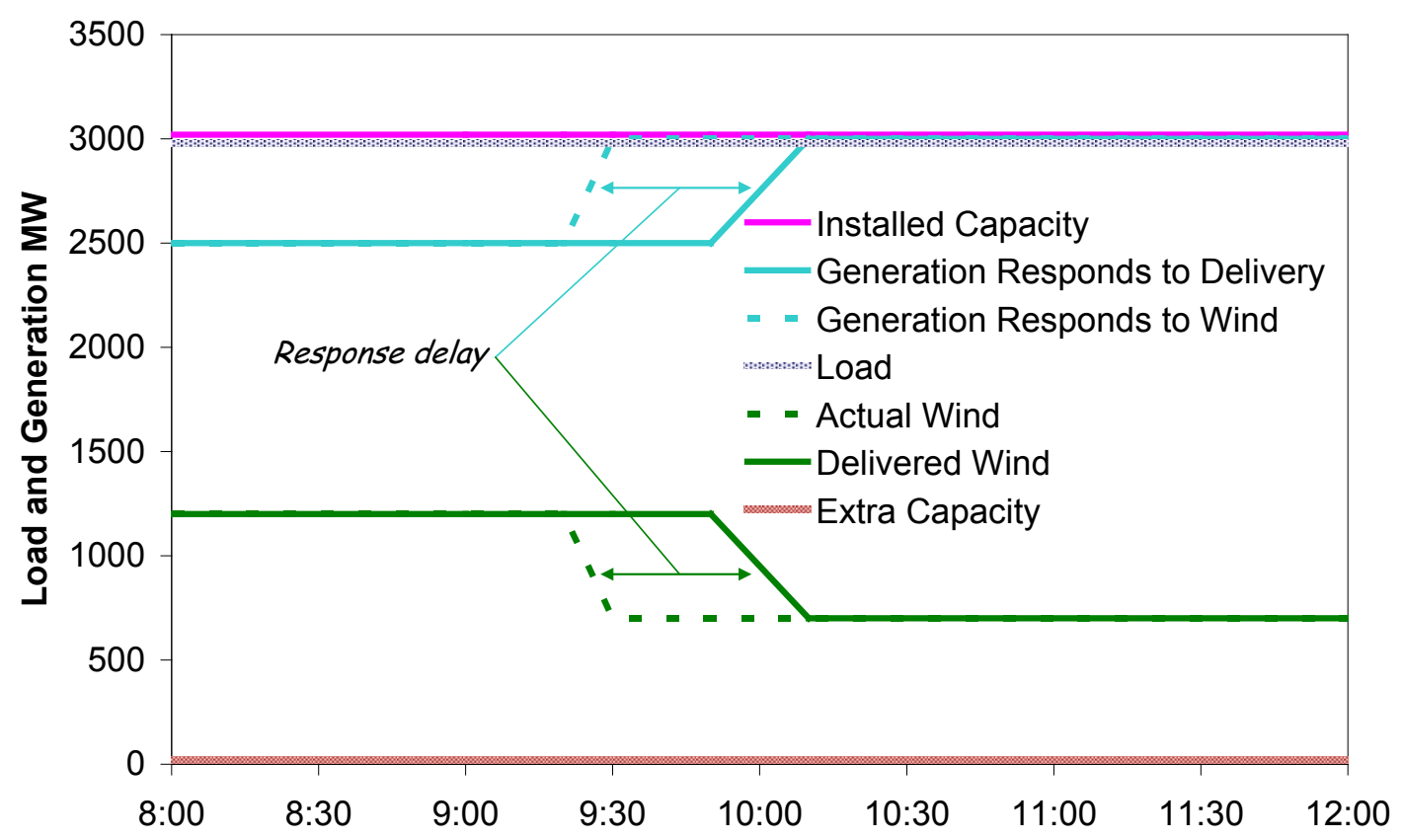

Figure 6. The BA that receives the wind does not get a capacity benefit, only a delay in response speed.

The extra capacity requirement on the host can be eliminated if the receiving BA can respond to the change in wind output as quickly as the physical host was going to respond. This can be accomplished by several means, and will be discussed below. Figure 7 shows the impact on both BAs. When the wind output falls, as shown in the left panel of the figure, the host does not need to respond because the receiver does. In the right side of the figure, the dotted line shows the delayed response from the previous case that is no longer required. Instead, the receiver increases generation as the wind drops off. It seems clear from this example that the excess capacity need can be eliminated if the receiver has a way to quickly respond to the wind. ${ }^{2}$

\footnotetext{
${ }^{2}$ The receiving area response requirement may in fact be easier to meet when it is responding directly to changes in the wind. This is because inter-BA schedule changes occur over 20 minutes (10 minutes in the east) while the wind ramp may be moving at a slower rate.
} 
This can be accomplished in several ways:

- A dynamic schedule or pseudo-tie that dynamically moves the wind generation to the receiver's BA,

- Sub-hourly inter-BA scheduling,

- Faster market-clearing periods,

- Bi-lateral agreement between the BA, and

- Combined operation of the two BAs.
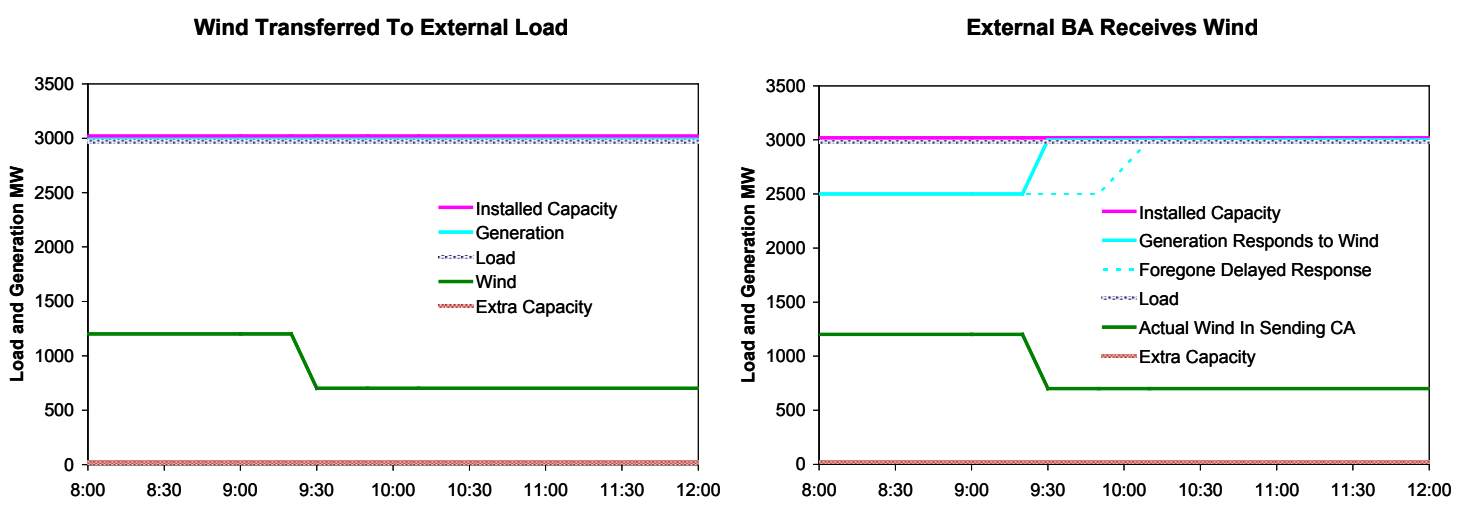

Figure 7. No additional capacity is required if the receiving (external) BA responds when the wind drops.

While a full dynamic schedule or pseudo-tie can be used to essentially move a wind generator (or any generator or load) from the physical host BA to the BA with the load it is serving, this is not always necessary. Providing a means to adjust inter-BA schedules every five to fifteen minutes may be simpler, cheaper, and more flexible in many cases. ACE diversity sharing can eliminate the need for the host BA to chase the wind generation while also allowing both BAs (and any others participating in the diversity scheme) to net variability and reduce total control action.

\section{Wind-Created Off-System Sales Opportunities}

So far, we have seen that no additional capacity is required when wind is used to serve load within the host BA. We have also seen that no additional capacity is required when wind serves load in an adjacent BA if the inter-BA schedules can be adjusted within the hour. Any additional capacity requirement is an artifact of inter-BA scheduling limitations and provides no real benefit to anyone. It is a true economic inefficiency.

Returning to the example of wind supplying load within the physical host BA examined above, we find that the addition of wind may create an opportunity for additional inter-BA sales for the nonwind generators. When wind is supplying load, the displaced non-wind generation is available to supply other loads. For example, if the wind energy can be predicted with certainty (we relax this assumption shortly), this creates the opportunity for increased off-system energy sales from 8:009:00, tailing off from 9:00-10:00 as shown in Figure 8. This energy sale from the existing conventional generation is made possible by the wind, because without the wind, the conventional generation would be needed to serve the internal BA load. 


\section{Wind Serves Internal BA Load}

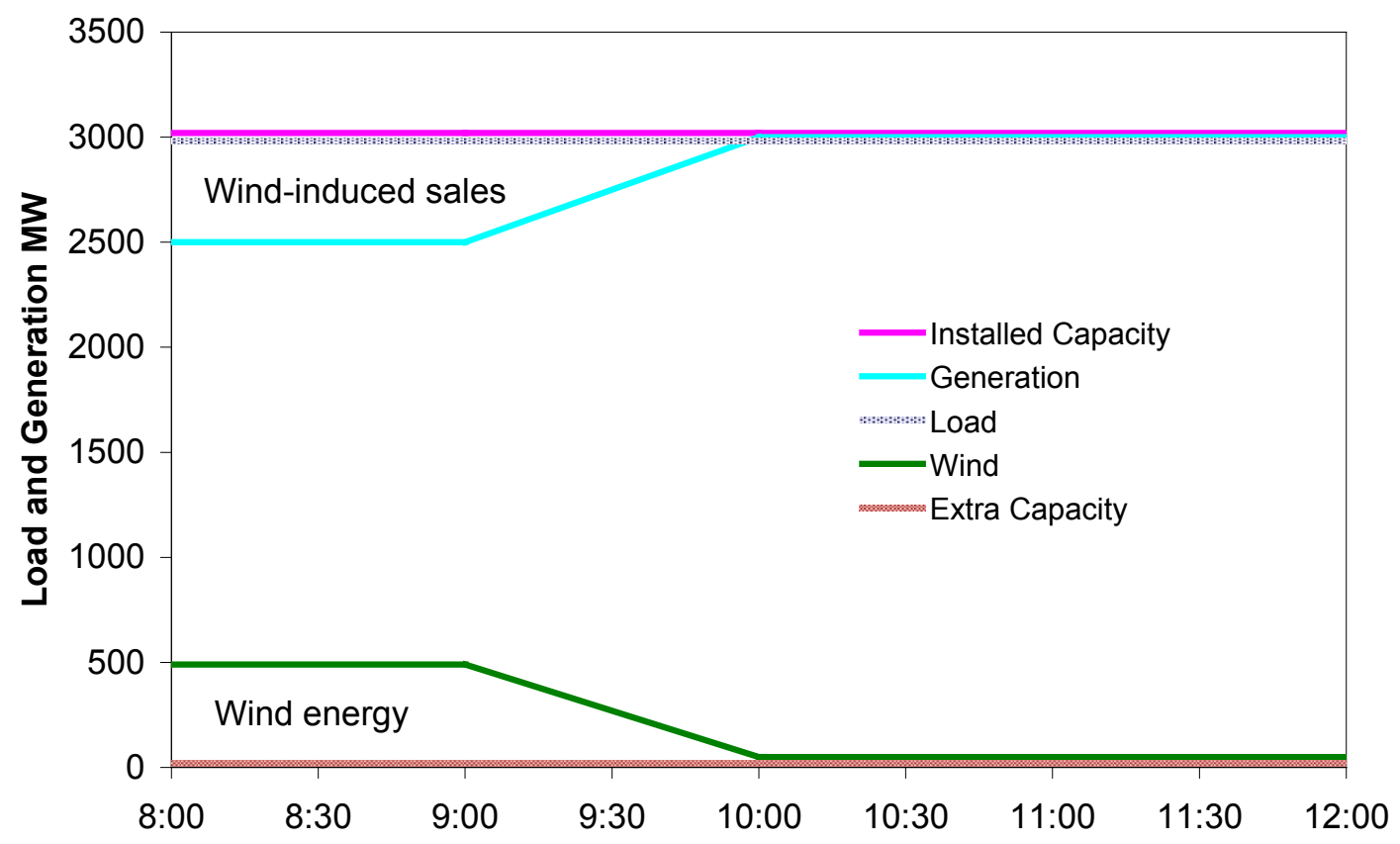

Figure 8. Wind serving load within the host BA makes it possible for additional energy sales that benefit the BA and its customers.

Imperfect load forecasts, wind forecasts and inter-BA scheduling restrictions create a problem, however (we ignore the impact of load forecast errors in this discussion and in Figure 8). As is the case of wind generation in one BA serving load in another BA examined earlier, the physical host BA may have to continue to supply the scheduled power for the remainder of the hour even if the wind drops unexpectedly. This will require additional generating capacity, similar to that shown in Figure 5 where wind is serving load in an external BA. Is this an additional capacity requirement imposed by wind? No. It is a limitation on the additional off-system sales opportunity created by the wind.

Because wind forecasts are not perfect, it is likely that the system operator would not want to enter in to a firm off-system sale for all of the conventional generation freed up by wind energy, allowing for some forecast error. To retain the simplicity of our analysis, we assume that some fraction of the wind forecast will be sold in the forward market, leaving some additional wind that could be sold in the real-time imbalance market. We arbitrarily divide the sale made possible by wind geometrically in half for illustration. As shown in Figure 9, the addition of a wind forecast error does not increase the capacity needs of the BA compared to the no-wind case. Because the actual wind is the same as in the previous case, the required physical response is also the same. However, forecast error does impact the nature of the off-system energy sales opportunity which the addition of wind creates. Based on the risk preferences of the system operator, the characteristics of the units on the dispatch stack, and the expected wind forecast error, there could be a difference in the way that the system is positioned going in to the operating hour. 


\section{Wind Serves Internal BA Load}

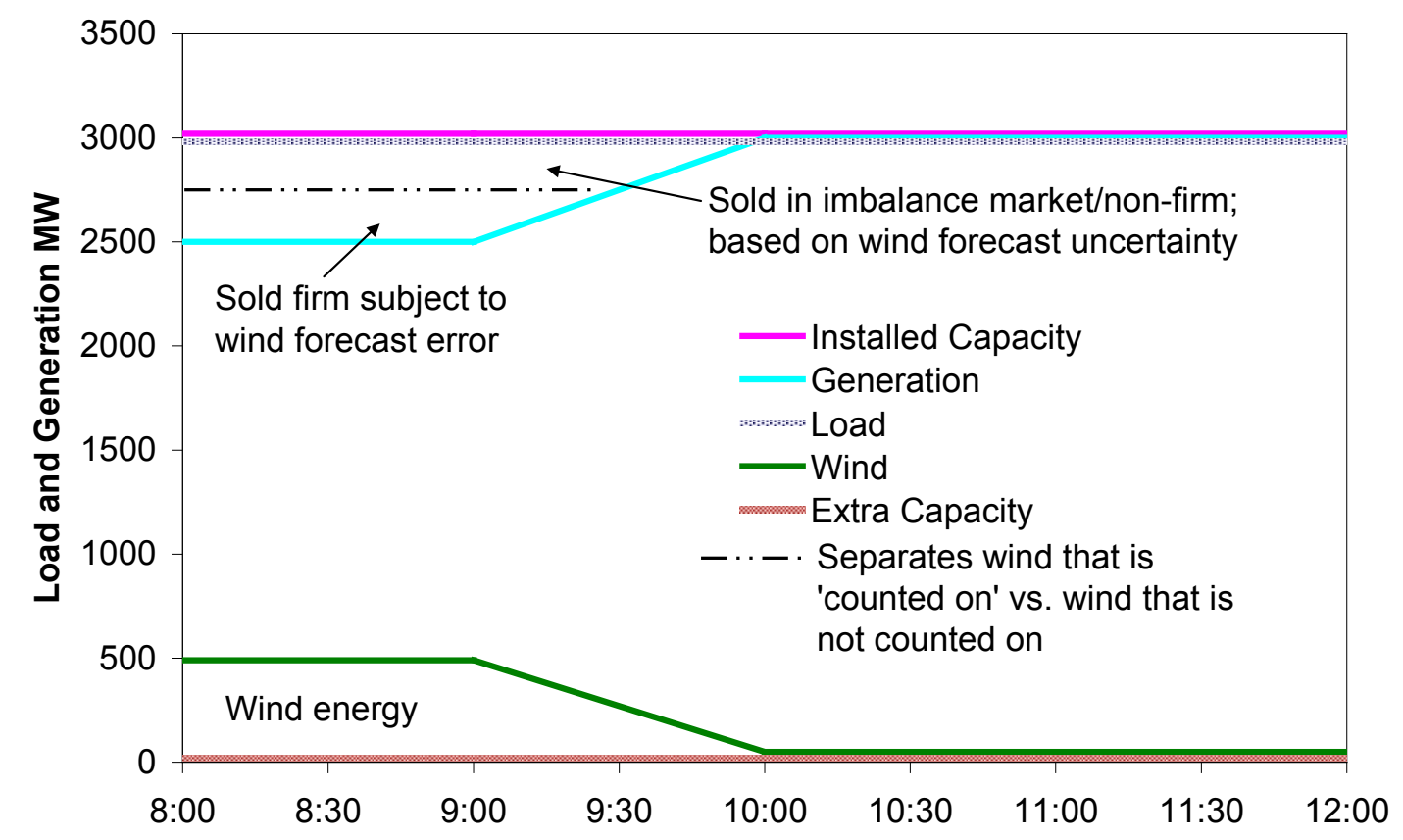

Figure 9. The amount of wind-induced energy sold may be less than the total wind energy based on wind forecast uncertainty.

In systems that have significant controllable hydro, for example, it may be possible to significantly reduce or eliminate the uncertainty of the off-system wind delivery wind forecast. The hydro system could potentially be used to store the wind energy for 2 hours before re-delivering it. Because the wind generation would then be known with certainty, the split between a firm and non-firm sale such as shown in Figure 9 would not be relevant because all wind could be sold as firm in the short term. 


\section{Example Using Public Data from Bonneville Power Administration}

The discussion so far has been primarily conceptual in nature, and has pointed out the impact of hourly schedules on inter-BA wind transfers. We now illustrate the potential impact of late gate closing and faster scheduling intervals on the excess capacity that the host BA must hold, based on the previous discussion.

Bonneville Power Administration (BPA) is a Federal Power Marketing Agency that markets energy from several large hydroelectric dams along the Columbia River, and operates its own balancing area. BPA has undertaken several analyses of the potential impact of an anticipated large wind buildout within its balancing area. One of the concerns of BPA is that a large proportion of the wind that is physically and electrically located in its BA is for export to other BAs. In addition, current practice in the Pacific Northwest (and across most of the Western Interconnection) restricts schedule changes to the top of the hour, with an associated ramp period within a 10-minute period either side of the hour for units to move to their scheduled position. As the previous discussion in this paper shows, the capacity requirements for the host BA can be significant under this type of scenario. To illustrate, we provide several simple examples to show how late gate closing and faster scheduling periods can be used to significantly reduce the adverse capacity impact on the host BA when large amounts of wind are exported outside of the host BA. We obtained data from BPA's public web site (http://www.transmission.bpa.gov/business/operations/wind/) for 2007. During that period of time, a maximum of 1,176 MW of wind was generated during the year, and the installed capacity increased as new wind was developed in the footprint. BPA provides 5-minute data for both load and wind on this web site. Peak BPA balancing area load was 9,425 MW. We made the simplifying assumption that $80 \%$ of the wind in BPA's footprint is for export, based on conversations with BPA personnel.

In keeping with the simple nature of our analysis, we applied wind persistence forecasting in all cases we analyzed. Although better forecasts can be obtained from commercial forecasters, the use of persistence forecasts is straightforward and can be easily replicated in other analyses. Real wind forecasts' accuracy is also often compared to persistence, allowing the interested reader to extrapolate as desired to other forecasting technologies.

Our first example shows the impact of a 2-hour persistence forecasting model (similar to one that was used in BPA's wind integration rate development process) and hourly schedules on the BPA system. The results appear in Figure 10. The upper panel shows the capacity requirement in the time domain for the full 8,760 hours of the year. The bottom panel shows the same data, but is organized as a duration curve. Over this year, the maximum capacity requirement imposed on BPA is $451 \mathrm{MW}$, compared to what a dynamic schedule would achieve. As indicated by the duration graph, there was a sharp fall-off in this maximum capacity requirement, indicating that most other hours experienced a lower capacity impact. The minimum capacity requirement is $-562 \mathrm{MW}$, and at first glance this appears to be an advantage for BPA because it implies a release of capacity during that hour. Although a reduction in capacity requirements may be attractive, BPA often has difficulty reducing its hydro generation during periods of high wind and low load. In situations like this, a large negative capacity requirement may result in the bottoming of BPA's generation during some periods of time. 


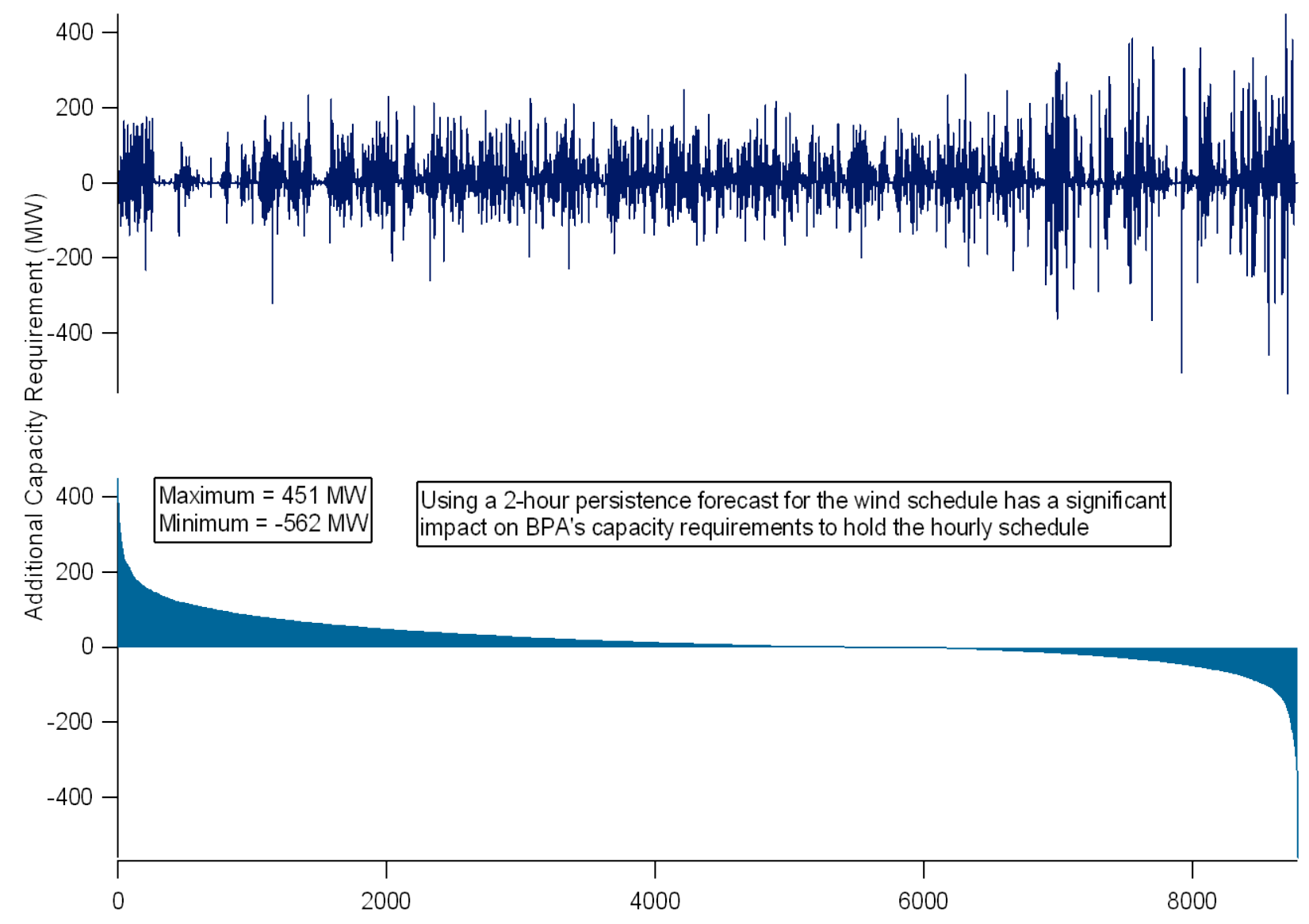

Figure 10. Impact of 2-hour persistence forecasts and hourly schedules on BPA's capacity requirements for inter-BA wind transfers. 
Even if the Pacific Northwest retained hourly schedules, delaying schedule-setting until just before the operating hour can significantly reduce capacity requirements. If hourly schedules could be set 10 minutes before the top of the hour, a 10-minute persistence model for wind shows a significant reduction in the capacity requirement for BPA. Figure 11 shows both the chronological and duration curve representation of the capacity requirement. Although it is not apparent from the graph, there are still some hours during which there is a negative capacity impact on BPA, although the capacity levels are too small to appear on the graph. The maximum capacity requirement using the 10-minute persistence schedule is $174 \mathrm{MW}$, compared to $451 \mathrm{MW}$ using the 2-hour persistence case.

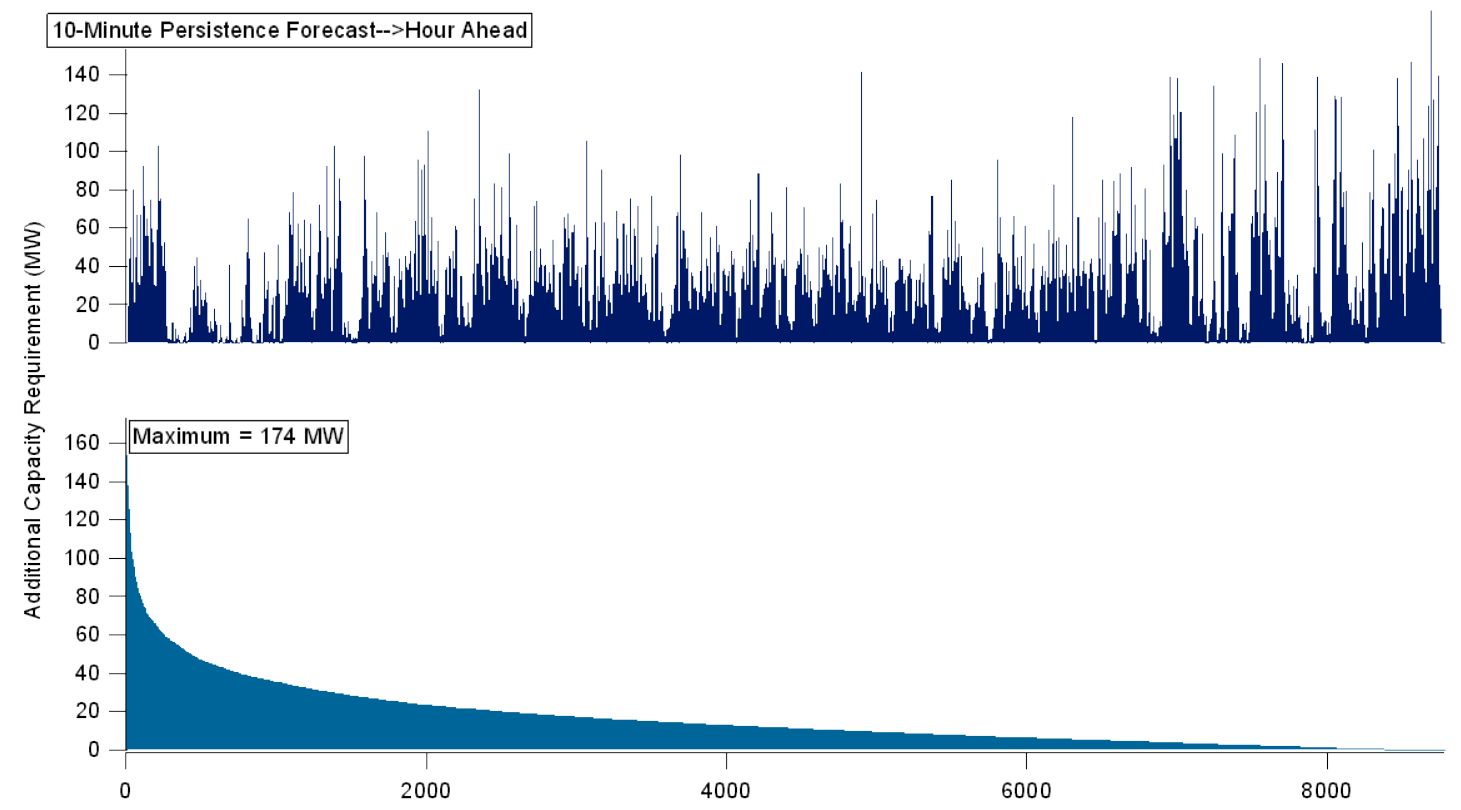

Figure 11. Capacity requirements for the host BA are reduced with a 10-minute wind persistence forecast for the next hour compared to a 2-hour persistence forecast. 
There are a number of potential alternative approaches that would help minimize the capacity requirements for the host $\mathrm{BA}$. If the receiving BA would agree to accepting wind on a 10-minute schedule, the host's requirement to hold the schedule until the next scheduling period would be substantially less than under an hourly schedule. Even moving to a 30-minute schedule would improve the capacity position of the host.

Calculating the impact of a 10-minute schedule adjustment between BAs requires faster data than we have. ${ }^{3}$ However, the overall forecast error is an indicator of the excess capacity requirement that inter-BA wind transfers impose on the host. Figure 12 shows a 1-week period with some significant wind ramps. Because each forecast considered here is persistence based, the forecasts will not do a good job of picking up these ramps. However, the graph shows a significant difference in the forecast errors from 2-hour persistence, 30-minute persistence, and a rolling 10-minute persistence forecast. This latter could potentially be used in conjunction with a rolling 10-minute scheduling protocol between the host and receiving BAs.

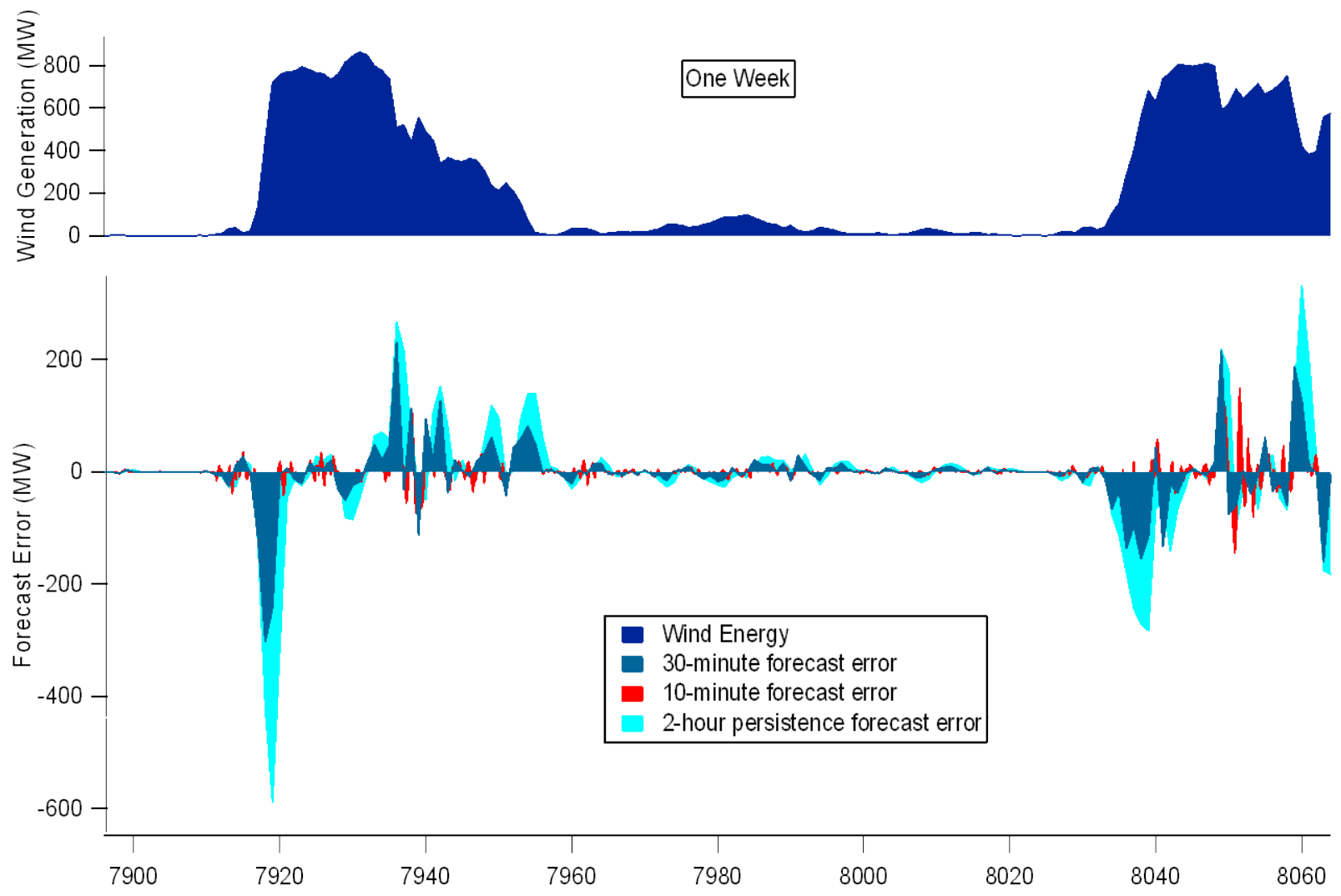

Figure 12. Forecast errors are an indirect indication of the excess capacity requirements on the host BA.

${ }^{3}$ Conventional generation ramping capability data is required in addition to wind and load data. 
BPA is pursuing an approach that will allow the curtailment of tags if the wind drops significantly below its hourly schedule. This accomplishes a within-hour schedule adjustment between the host and receiving balancing areas, reducing the unnecessary capacity requirement on the host.

\section{Other Capacity and Energy Considerations: Regulation and Load Following}

In prior work we have discussed regulation as a capacity service, and have demonstrated that load following capacity can often be extracted at low-cost or no-cost from sub-hourly energy markets. In this section we describe conditions under which it may make sense for wind to supply regulation services. We also provide additional evidence that in spite of volatility in sub-hourly energy prices, load following appears to be a very low-cost service in several well-developed markets in the U.S.

\section{Regulation: Possibly From Wind}

Though wind plants have a relatively small impact on power system regulation requirements regulation is important because it is the most expensive ancillary service (Table 1). Unlike spinning, non-spinning, and supplemental contingency reserves, where prices typically fall to near zero at night, regulation prices typically remain high at night. Wind can compound regulation supply difficulties when it displaces conventional generation and leaves fewer conventional generators available to supply regulation. Interestingly, it may be attractive for wind plants to provide minuteto-minute regulation under some conditions.

Table 1. 2008 annual average ancillary service prices: \$/MW-hr.

\begin{tabular}{|c|c|c|c|c|}
\hline & $\frac{\text { California }}{(\operatorname{Reg}=\text { up }+d n)}$ & $\frac{\text { ERCOT }}{(\operatorname{Reg}=\text { up }+ \text { dn })}$ & New York & $\frac{\text { New England }}{\text { (Reg +"mileage") }}$ \\
\hline Regulation & 33.4 & 43.1 & 59.5 & 13.75 \\
\hline Spin & 6.0 & 27.2 & 10.1 & 1.67 \\
\hline Non-Spin & 1.3 & & 3.1 & 1.21 \\
\hline Replacement & 1.4 & 4.4 & 1.1 & \\
\hline
\end{tabular}

Regulation is the most expensive ancillary service because it is expensive for generators to supply regulation. A generator incurs four types of costs when supplying regulation:

- Efficiency loss (throttling losses)

- Environmental costs

- Increased wear-and-tear, increased maintenance, reduced equipment life

- Opportunity costs in the energy market

The opportunity costs dominate but let's examine each cost component in turn. A large coal fired steam plant, for example, must change operating modes when supplying regulation. To supply energy most efficiently the plants typically operate with steam valves wide open in "boiler-follow" mode. Output is controlled by changing the fuel supply to the boiler. This type of control results in high efficiency but slow and inaccurate control. In order to get the faster response needed for 
regulation it is necessary to partially close the throttling valve and modulate the flow of steam to the turbine. This reduces total plant efficiency somewhat. The reduced efficiency necessarily results in increased emissions per MWH of energy produced as well. Both of these costs can be quantified for each generator. ${ }^{4}$

Supplying regulation requires the generator to constantly change output in response to system operator commands. This likely increases wear-and-tear, increases maintenance cost, and may shorten equipment life. Though these costs are difficult to quantify (reduce equipment life may not be evident for years) the generator owner has to estimate them in order to include them in their bid to supply regulation.

Opportunity costs are typically the largest costs for supplying regulation. A $600 \mathrm{MW}$ generator that offered to supply $12 \mathrm{MW}$ of regulation, for example, would have to reduce average scheduled output to $588 \mathrm{MW}$ in order to be ready to swing between $576 \mathrm{MW}$ and $600 \mathrm{MW}$ (588 MW of energy and \pm 12 MW of regulation). This will result in lost energy-market profit for the generator which the generator will have to recover from the regulation price. Regulation prices are, consequently, a function of the real-time energy prices and regulation prices are typically more volatile than energy prices.

Figure 13 shows how the cost a typical $600 \mathrm{MW}$ coal fired generator incurs to provide regulation changes as a function of the market price for energy. ${ }^{5}$ The generator's ramp rate lets it supply $2 \%$ of its capacity (12 MW) as regulation. It has a $200 \mathrm{MW}$ minimum load. The marginal production cost (based primarily on fuel cost) is $\$ 14.52 / \mathrm{MWH}$ at full output and climbs to $\$ 18.38 / \mathrm{MWH}$ at minimum load. This generator suffers a $0.75 \%$ efficiency penalty (including increased O\&M and reduced equipment life) on all energy produced when supplying regulation and it is applied as a fixed penalty at all loads.

When the spot energy price is in the $\$ 15-18 / \mathrm{MWH}$ range this coal fired generator makes no profit but its fuel and operating costs are covered so it incurs no losses either. It is essentially indifferent to the power level it is operating at. It could generate $600 \mathrm{MW}$ but it suffers no lost profits if it backs down to $588 \mathrm{MW}$ in order to provide $12 \mathrm{MW}$ of regulation. It will suffer an efficiency loss, however. The cost to generate the $588 \mathrm{MW}$ of energy will rise by $\$ 0.23 / \mathrm{MWH}$ or $\$ 136 /$ hour. This increased cost is incurred only because the generator changes operating modes to supply regulation and the cost should be recovered from the regulation sale. The generator would have to charge at least $\$ 11.32 / \mathrm{MW}-\mathrm{hr}$ of regulation $(\$ 136 / 12 \mathrm{MW})$ in order to break even. As the price of energy rises the generator could make additional profits from the sale of energy. With energy at $\$ 40 / \mathrm{MWH}$ the generator would loose $\$ 25.48 / \mathrm{hr}$ for every MW of regulation it supplied. Adding the $\$ 25.48$ to the $\$ 11.32$ results in a regulation cost of $\$ 36.80 / \mathrm{MW}-\mathrm{hr}$ of regulation.

\footnotetext{
${ }^{4}$ Some hydro plants incur similar efficiency penalties when regulating.

${ }^{5}$ This relationship is true in the vertically integrated world as well but the cost of regulation from the generator is a function of system lambda, the marginal energy cost.
} 


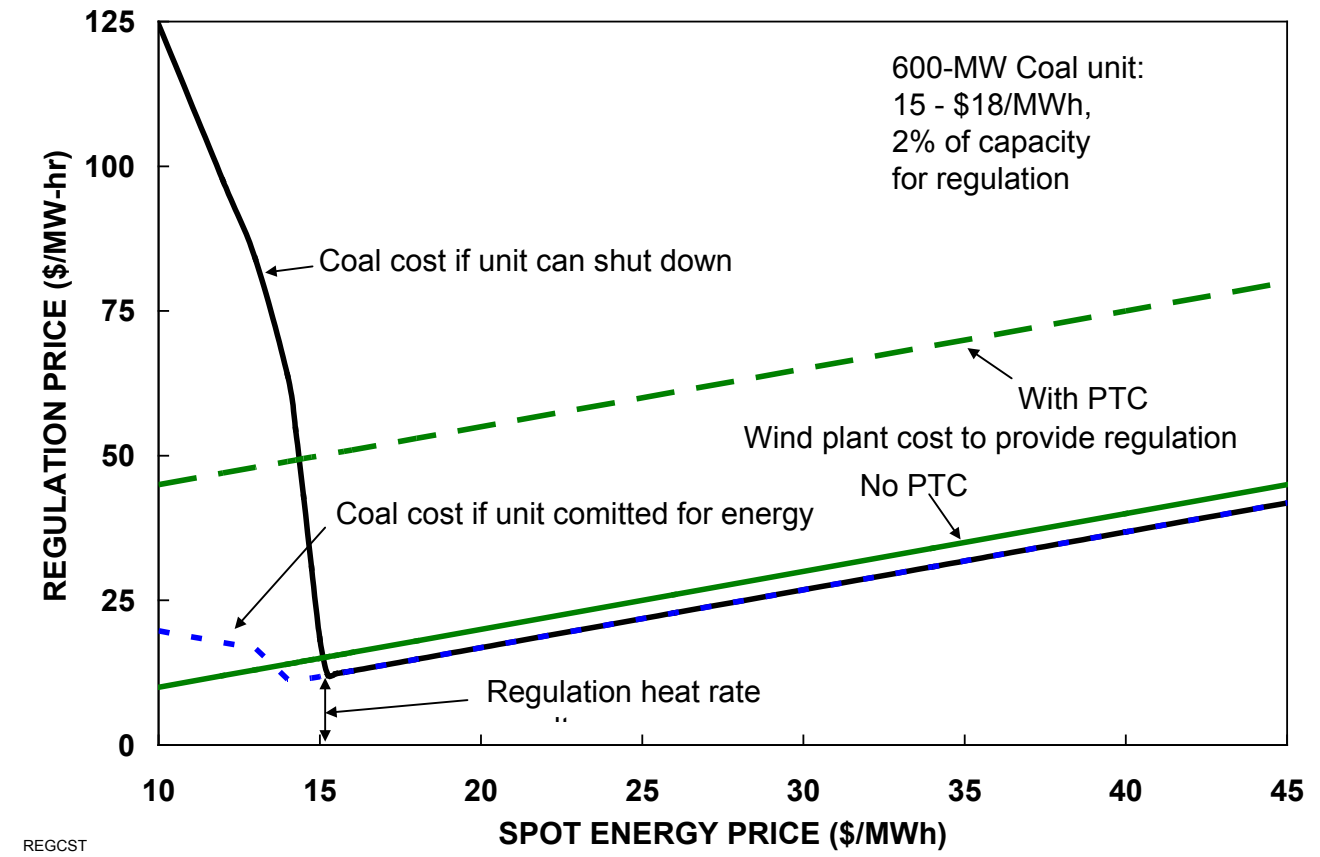

Figure 13. The cost of supplying regulation is a function of the price of energy for both thermal and wind generators.

Ideally regulation should be supplied by the marginal generator. In that case there is no energy opportunity cost and the regulation cost is minimized. Supplying regulation requires the generator to be on automatic generator control and to have significant response capability. The marginal generator is often not on the margin long enough to justify the expense of giving it regulating capability. Consequently regulation is often obtained from generators farther down in the dispatch order and the price of regulation stays high.

Things are more complex at lower energy prices. If the price of energy is only $\$ 10 / \mathrm{MWH}$ the generator looses money on every MWH it generates. If the unit can turn off it will, but it might be forced to stay on overnight if it wants to sell energy the next day and it has a lengthy shut-downstartup cycle time. Assuming the generator is forced on anyway (blue dotted line) the cost to supply regulation is the increased expense associated with operating at $212 \mathrm{MW}$ instead of the $200 \mathrm{MW}$ minimum load, plus the efficiency and wear-and-tear costs. Regulation costs get very high (solid black line) if the generator could have turned off and is being held on simply to provide regulation. In that case regulation is responsible for the losses incurred while producing all $212 \mathrm{MW}$ of energy, not just the $12 \mathrm{MW}$ needed to create maneuvering room.

It is reasonable to assume that it would not be economically attractive for wind generators to supply regulation. With zero marginal cost the opportunity cost for a wind plant in the energy market is higher than any other type of generator. ${ }^{6}$ But thermal generators suffer efficiency penalties when they provide regulation, partially offsetting the fuel savings. A wind plant's cost for providing regulation might not be that much higher than a coal plant's cost as shown by the solid green curve

\footnotetext{
${ }^{6}$ This is true for non-storage solar and run-of-river hydro as well.
} 
in Figure 13, assuming there are not significant wear-and-tear costs for the wind plant to regulate. In fact, the wind plant looks like an attractive source of regulation when low loads result in low energy prices and thermal generators are forced to minimum loads. The wind plant might make more money selling regulation than selling energy under specific conditions.

The production tax credit (PTC) and any carbon or emissions credits complicate the analysis. A simple PTC essentially gives the wind plant a negative marginal cost, raising its opportunity costs when regulating. A $\$ 35 / \mathrm{MWH}$ PTC is shown by the dashed green line in Figure 13. This would make wind an attractive regulating resource only in very limited circumstances. If the higher emissions associated with the reduced efficiency incurred when the thermal plant regulates were accounted for it might be appropriate to give a regulating wind plant the full PTC. Proper emissions and carbon accounting will give the regulating wind plant credit if a carbon tax is imposed.

All of this assumes that wind plants can provide minute-to-minute power system regulation under automatic generation control. Evidence from the Horns Rev wind plant operations in Denmark and from commissioning tests performed by General Electric on a $60 \mathrm{MW}$ wind plant in Quebec indicate that a properly equipped wind plant can provide regulation. Further, the quality of control (speed and accuracy) appears to be much better than that offered by large thermal generators. Figure 14 shows the plant output from both facilities while they were under power system control. Of course, wind plants are limited in their ability to regulate by the available wind. Like a conventional regulating power plant, the wind plant must back down from full production to create maneuvering room for up-regulation. The wind plant has the added restriction that it must back below both its name-plate MW capability and below the capability supported by the current wind. 

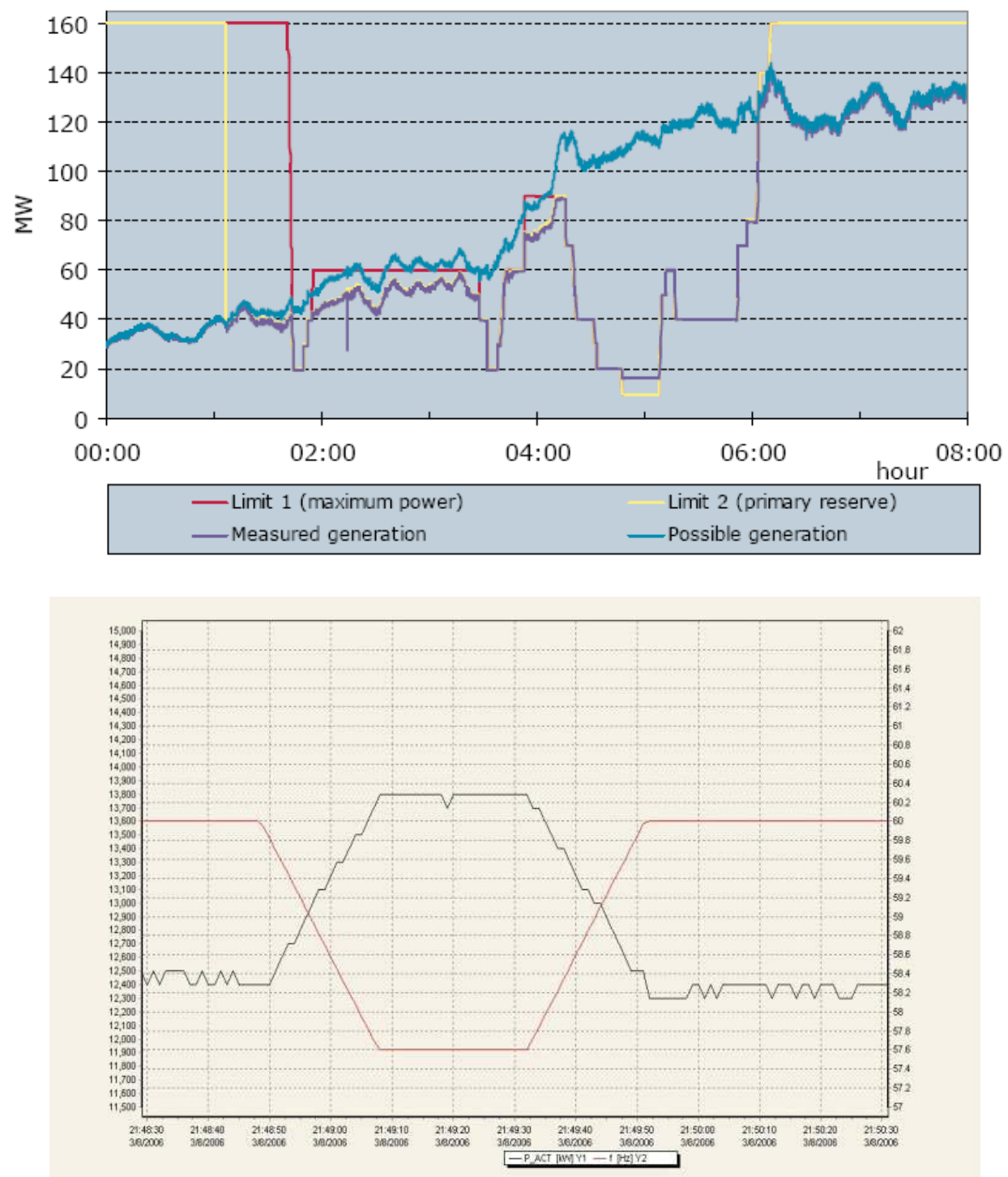

Figure 14. The Horns Rev wind plant regularly supplies regulation (upper graph - Peter Borre Eriksen's). GE “Grid Friendly Wind Farm Controls” response capability appears to match regulation requirements (lower graph - Nick Miller).

There is a further concern with wind providing regulation. If the wind dies down the power system will loose its regulation resource as well as the energy supply. Clearly this is a problem at high loads but it is likely not a problem at light loads when wind is most likely to supply regulation. As the wind dies down and conventional generators have to replace the lost wind they will move off of minimum load, creating regulating capability within the conventional generation fleet. Fortunately the regulation resource that is enabled is relatively low cost. 


\section{Is Load Following A Capacity Service Or a Byproduct of Fast Energy Markets and the Economic Dispatch Stack?}

Load following is an interesting power systems concept. In one sense it is a slightly slower version of minute-to-minute regulation, and regulation is the most expensive ancillary service. In another sense load following is a slightly faster version of hourly energy scheduling and there is no maneuvering cost in the hourly energy market, only energy costs. In fact load following can be either, depending on the response capabilities of the currently available energy producing generators.

When wind is providing energy to its native BA, we have shown that there is no need for additional capacity, relative to the no-wind case. It is clear that wind will likely impose additional ramping requirements on the system. Before discussing the impact of wind on ramping in more detail, we first examine the relationship between load following and energy markets. Our discussion can easily be applied to vertically integrated utilities that practice economic dispatch, however, for the discussion we focus on the case of an open energy market.

To sell energy into a market, it is necessary for the generator to be maneuvered to the appropriate level of output. Base-load units are typically not required to maneuver much as they supply energy. The unit commitment process selects the unit for operation; the unit is started and brought to its rated capacity over a period of hours. The low operating cost of base-load units (below the market clearing price) allows them to participate in energy markets by continuously operating at their full economic output.

Intermediate and peaking units operate differently. Their somewhat higher operating cost is not always below the energy market clearing price so they do not participate in the market unless the clearing price is at or above their cost of generation. These units may not run at night when prices are low, for example, but instead operate and sell energy during the day. In order to sell into a given hourly market, the intermediate unit must position itself so that it can sell the prescribed energy for the duration of the market period. In subsequent market periods, the generator must again move to a new output level if it will sell more or less energy than in the first period, depending on its operating cost and the market clearing price. Failure to respond to market prices seriously hurts an intermediate unit. The unit incurs a lost opportunity if the market price is high and it does not turn on and ramp up to sell. Similarly, the intermediate unit looses money if the market price is below its operating cost and it does not turn off or minimize production.

Energy markets are able to obtain a great deal of load following response from intermediate and peaking generators without explicitly paying for it. This is very different from regulation where the system operator must purchase a specific regulation ancillary service.

Most of the time the intermediate and peaking units can position themselves as needed, and each interconnection has procedures for allowing for the required ramps so that at the top of the hour, units have achieved their desired level of output. However, there are times when the generators can't move quickly enough, which results in very high energy prices for a short duration of time. This situation can arise if the dispatch stack is not sufficiently deep or if sufficient ramping capability does not exist. Figure 15 shows an example of a base-load unit that is on the margin that is unable to ramp quickly enough between 8:30 and 9:00 to meet the load, which ramps quickly during this time. Instead, fast maneuverable generation, such as a peaking unit with very high marginal cost, must be 
dispatched to cover the ramp. Once the base-load unit catches up to the load, the peaking unit is no longer needed. If the energy price is set based on the marginal unit, the price will rise from $\$ 10.00 / \mathrm{MWh}$ at 8:30 to $\$ 90 / \mathrm{MWh}$ from 8:30-13:00, and then fall back to $\$ 10 / \mathrm{MWh}$. In this case, the energy price spikes because the marginal generator is not nimble enough to fully participate in the energy market starting at 9:00.

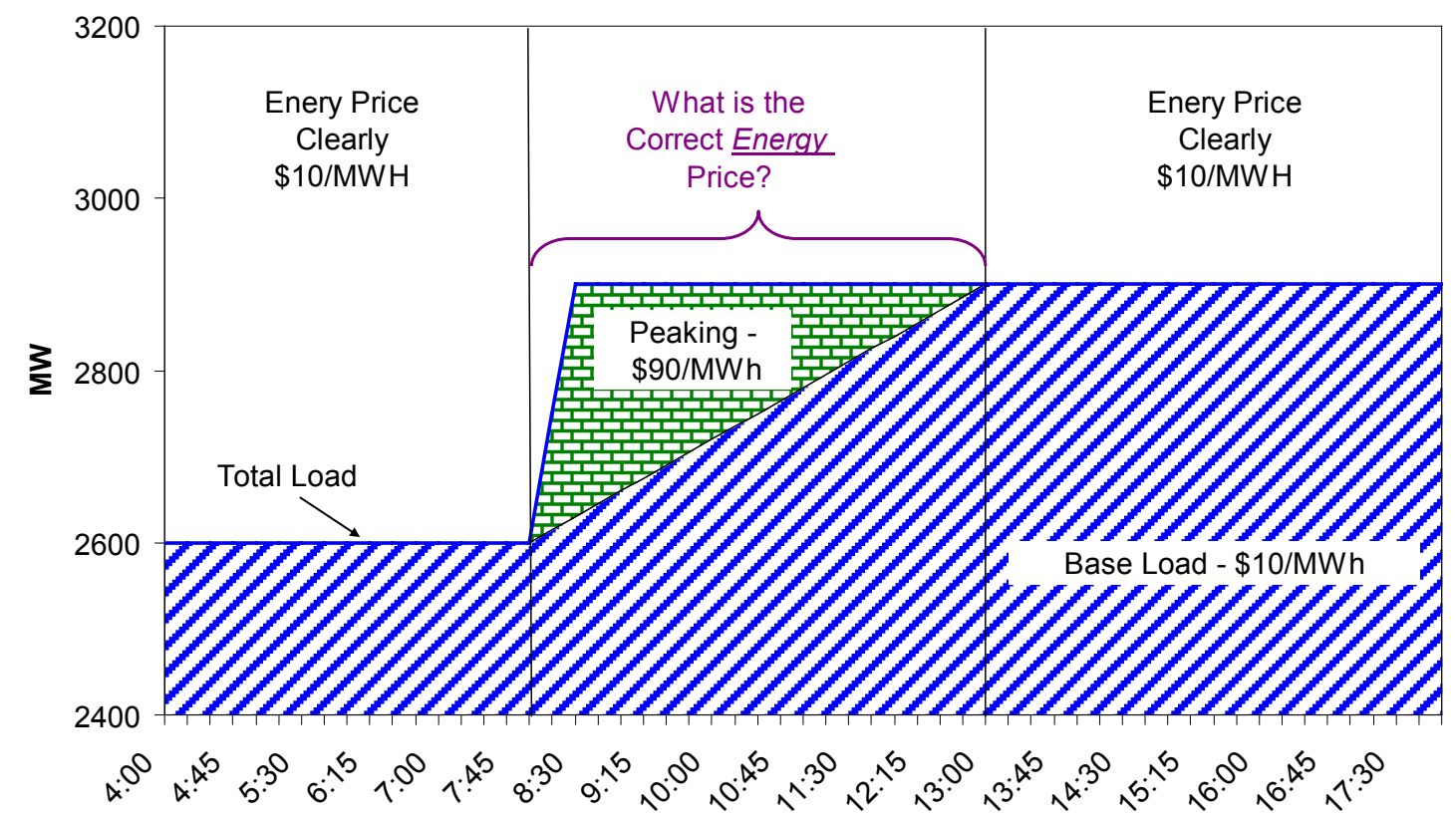

Figure 15. Load following is a distinct service that is needed if ramping capability impacts the energy market unit selection.

Conversely, if the load had followed the capability of the base-load unit, the required load following would have simply been extracted from the energy market. The generator would have been able to position itself to provide energy for load, and no distinct load following service would have been needed.

In this example, no additional capacity is needed to maintain system balance. Different capacity is required, capacity with a faster ramp rate, but additional capacity is not needed. Wind ramping can further exacerbates the ramping shortfall shown in Figure 15, but again it does not require additional capacity. Instead, wind imposes a need for more flexible capacity. If that flexibility cannot be provided from the energy market, it must be provided by a load following market or by emergency provisions.

So, load following can be either an expensive service, distinct from energy delivery, as in the green portion of Figure 15, or load following can simply be the repositioning of the energy producing generators as they move from one sales opportunity to the next. As in Figure 15, the expense would be expected to show up as high energy prices during high ramping hours if the energy producing generators did not have excess ramping capability.

In a previous study we examined the excess ramping capability available in the thermal generators of three very different balancing areas. We showed previously that there is excess maneuvering 
capacity in the energy production fleet and load following would be expected to have little or no cost Figure $16 .^{7}$

\section{Sub-Hourly Energy Markets}

NYISO, ISO-NE, CAISO, and MISO all operate five minute energy markets. Prices in these markets are highly volatile, even within the hour. The first three numeric columns in Table 2 show the annual average prices from the day-ahead hourly markets, the hour-ahead hourly markets, and the five minute markets. The fourth column shows the average within-hour price range from the five minute markets for each hour. These are dramatic price swings that occur almost every hour. The ISOs adjust price signals in order to move energy supplying generators up and down to follow the net demand.

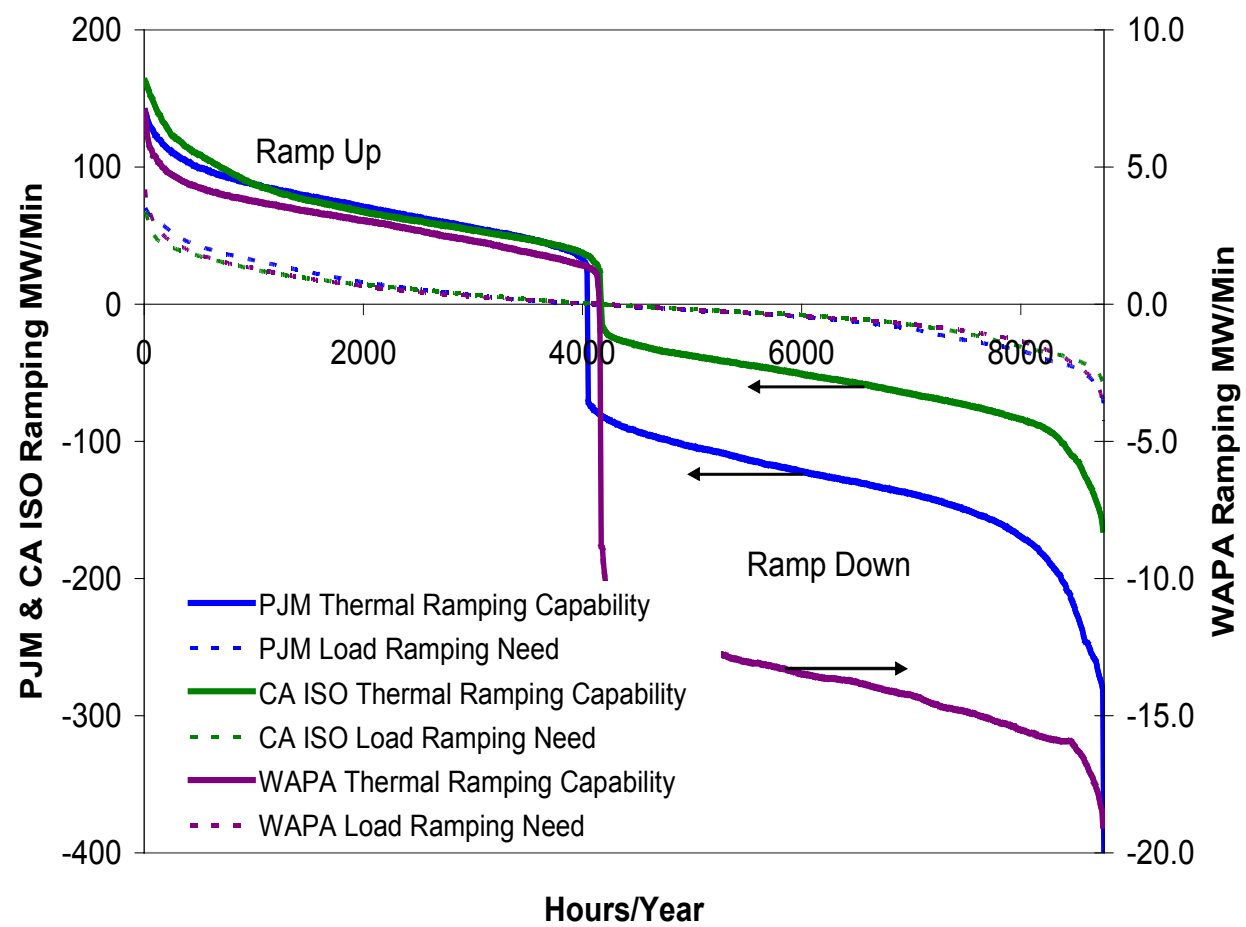

Figure 16. Earlier analysis of three different balancing areas showed that all three had excess load following capability inherent in the conventional thermal generation mix.

\footnotetext{
${ }^{7}$ B. Kirby, M. Milligan, 2005, A Method and Case Study for Estimating The Ramping Capability of a Control Area or Balancing Authority and Implications for Moderate or High Wind Penetration, American Wind Energy Association, WindPower 2005, May.
} 
Table 2. Annual average prices for 2008 show consistence between hourly energy markets. Subhourly markets show strong volatility.

\begin{tabular}{ccccc}
\hline ISO & $\begin{array}{c}\text { Day-Ahead } \\
\text { \$/MWH }\end{array}$ & $\begin{array}{c}\text { Hour-Ahead } \\
\text { \$/MWH }\end{array}$ & $\begin{array}{c}\text { 5-Minute } \\
\text { \$/MWH }\end{array}$ & $\begin{array}{c}\text { Average Within-Hour } \\
\text { 5-Minute Range } \\
\text { \$/MWH }\end{array}$ \\
\hline NYISO & $\$ 67.70$ & $\$ 64.93$ & $\$ 63.31$ & $\$ 91.18$ \\
ISO-NE & $\$ 81.38$ & $\$ 80.76$ & $\$ 81.22$ & $\$ 24.40$ \\
CAISO & & $\$ 69.78$ & $\$ 68.32$ & $\$ 59.87$ \\
MISO & $\$ 49.99$ & $\$ 48.62$ & $\$ 48.71$ & $\$ 67.75$ \\
\hline
\end{tabular}

Interestingly there is surprising consistence between the annual average hourly prices for day-ahead, hour-ahead, and five-minute prices. Average hour-ahead and five minute prices differ by $\$ 0.46$ to $\$ 1.62 / \mathrm{MWH}$. Average day-ahead prices differ by $\$ 0.16$ to $\$ 4.39 / \mathrm{MWH}$. Interestingly the five minute prices (average) are typically slightly less than the hour-ahead or day-ahead prices. Clearly the faster maneuvering generators in the five-minute markets are not commanding a price premium for their response capability. So, while the prices within the hour are moving dramatically in order to obtain sub-hourly movement from energy producing generators (load following), there is essentially no overall cost for obtaining this response: very different from the high price for minute-to-minute regulation shown in Table 1. The fact that this pattern is repeated across four large, mature, well operating energy markets for long stretches of time indicates that this is not an anomaly.

There are patterns within this variability but in all cases the pattern magnitudes are much smaller than the average ranges. There is a great deal of random movement, similar to regulation, along with a smaller amount of predictable motion, similar to the daily load swing. Figure 17 shows the average difference between the five minute price at each interval (hour of the day and minutes into the hour) versus the hourly average of the twelve five-minute prices for the hour for MISO.

There is a strong and consistent low price for the first few minutes of the $7 \mathrm{am}$ hour, for example, with a higher price at the end of the hour. This is likely needed to move generation down at the start of the hour to counter block schedules that are starting at the top of the hour. The block schedules (on during the day, off at night) match the overall load pattern but they do not match the smooth ramp which load exhibits. Responsive generation is needed to counter the sharp block "edges". Similarly, prices are high at the start of the 22:00 hour, likely because block schedules are ending for the day. Still, the graph scale is only $\pm \$ 20 / \mathrm{MWH}$ while the average hourly range for five minute prices in MISO was $\$ 67.75 / \mathrm{MWH}$. There is a lot of random movement not captured in the average pattern. 


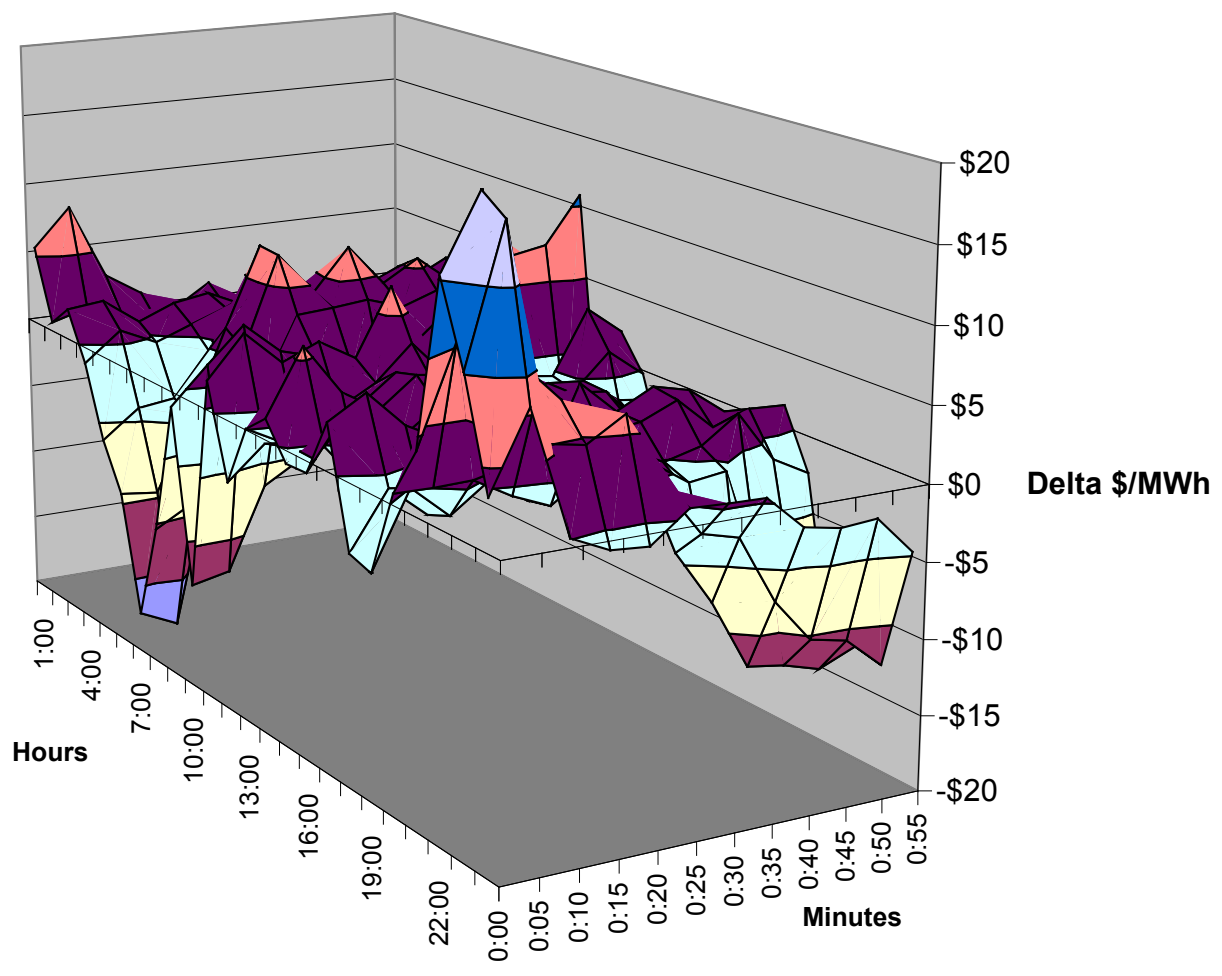

Figure 17. Average five-minute market price differences in MISO show some pattern.

\section{Conclusions: Minimizing Capacity Requirements and Wind Integration Costs}

We have shown that capacity requirements for wind generation being transferred from one BA to another are an artificial artifact of the hourly scheduling practices. Worse, they are useless and wasteful because the receiving BA does not gain any benefit from the capacity the sending BA has to dedicate to firming the wind generation schedule for the remainder of the hour. Sub-hourly scheduling allows the receiving BA to respond immediately to wind variations, eliminating the need for the sending BA to hold reserves. Better still; the two BAs can share their overall variability (wind and load) to reduce the control response required by each. This can be done by combining BAs or through an ACE diversity interchange.

We also show that load following itself can be either a specific service, like regulation, or it can be extracted from the energy supplying generators in the normal course of their selling energy. In the latter case there is no cost to the power system. A simple example showed that energy prices can be dramatically impacted if there is no load-following ramping service and the power system runs short of response capability. Fast ramping generation would have to be started, distorting the energy price, if the available economic generators were not able to maneuver fast enough. This market impact should be readily detectable by market monitors. An earlier work showed that, for at least three 
diverse balancing areas, the power system typically has ample ramping capability available in from the conventional generators that are supplying energy.

An examination of price data from four ISOs that operate five-minute markets shows that there is great within-hour price volatility, indicating strong use of generators on the margin to provide response. This response is obtained at little or no cost as shown by the fact that the annual average price from the five-minute markets is essentially the same as the price from the hour-ahead and dayahead markets. So far there does not appear to be a price premium required for load following. This is very different than for minute-to-minute regulation which is the most expensive ancillary service.

Finally, regulation may be an attractive service for some wind plants to sell at some times. The low marginal cost of wind generation results in a high opportunity cost for providing regulation but this is partly offset by the efficiency loss thermal generators incur when regulating. Wind may be an attractive regulation provider when energy prices are very low, likely during minimum load conditions at night. 


\section{REPORT DOCUMENTATION PAGE}

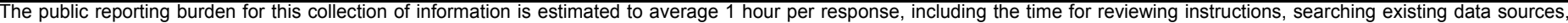

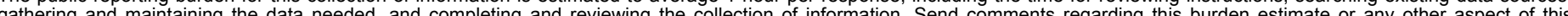

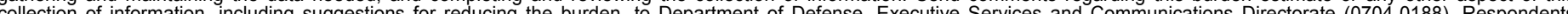

should be aware that notwithstanding any other provision of law, no person shall be subject to any

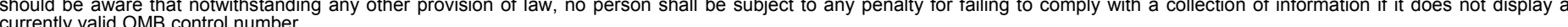

PLEASE DO NOT RETURN YOUR FORM TO THE ABOVE ORGANIZATION.

\begin{tabular}{l|l|l|l} 
1. REPORT DATE (DD-MM-YYYY) & 2. REPORT TYPE & 3. DATES COVERED (FrOm - TO)
\end{tabular}

July 2009

Technical Report

4. TITLE AND SUBTITLE

Capacity Requirements to Support Inter-Balancing Area Wind

Delivery

5a. CONTRACT NUMBER

DE-AC36-08-GO28308

5b. GRANT NUMBER

5c. PROGRAM ELEMENT NUMBER

6. AUTHOR(S)

M. Milligan and B. Kirby

5d. PROJECT NUMBER

NREL/TP-550-46274

5e. TASK NUMBER

WER95501

5f. WORK UNIT NUMBER

7. PERFORMING ORGANIZATION NAME(S) AND ADDRESS(ES)

National Renewable Energy Laboratory

1617 Cole Blvd.

8. PERFORMING ORGANIZATION REPORT NUMBER

Golden, CO 80401-3393

NREL/TP-550-46274

9. SPONSORING/MONITORING AGENCY NAME(S) AND ADDRESS(ES)

10. SPONSOR/MONITOR'S ACRONYM(S)

NREL

11. SPONSORING/MONITORING AGENCY REPORT NUMBER

12. DISTRIBUTION AVAILABILITY STATEMENT

National Technical Information Service

U.S. Department of Commerce

5285 Port Royal Road

Springfield, VA 22161

13. SUPPLEMENTARY NOTES

14. ABSTRACT (Maximum 200 Words)

This paper examines the capacity requirements that arise as wind generation is integrated into the power system and how those requirements change depending on where the wind energy is ultimately delivered.

\section{SUBJECT TERMS}

Wind; grid integration; systems integration; capacity credit; integration costs; wind energy value, electric system; wind power; utility

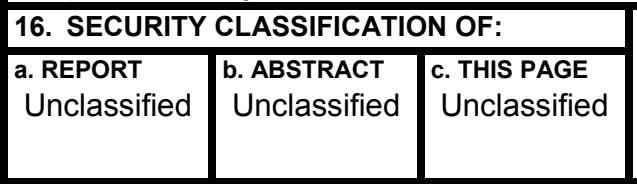

\begin{tabular}{|c|c|}
\hline $\begin{array}{l}\text { 7. LIMITATION } \\
\text { OF ABSTRACT }\end{array}$ & $\begin{array}{l}\text { 18. NUMBER } \\
\text { OF PAGES }\end{array}$ \\
\hline UL & \\
\hline
\end{tabular}

19a. NAME OF RESPONSIBLE PERSON

19b. TELEPHONE NUMBER (Include area code) 